\title{
Comparison of The Effects of Remifentanil and Fentanyl Combined with Desflurane on Intraoperative Hemodynamic Parameters and Postoperative Recovery Period in Anesthesia for Day Case Surgery
}

\author{
Murat Doğan ${ }^{1}$, Ezgi Güngördü ${ }^{1}$ \\ ${ }^{1}$ Department of Anesthesia and Reanimation Clinics, University of Health Sciences, Bakirkoy Dr. Sadi Konuk Teaching and \\ Research Hospital, Istanbul, Turkey
}

Received: 09 February 2020, Accepted: 12 April 2020, Published online: 30 April 2020

(C) Ordu University Institute of Health Sciences, Turkey, 2020

\begin{abstract}
Objective: We aimed to compare the effects of two different opioids, fentanyl and remifentanil with shortacting inhalation agent, desflurane on intraoperative hemodynamics and recovery quality in the postoperative period in anesthesia for day case surgery.

Methods: A prospective randomized case control study was carried out at Anesthesia and Reanimation Clinics of The Istanbul Education and Research Hospital with the approval of the local ethics committee between 2001-2002. The study population $(n=100)$ who has arthroscopic knee surgery was composed of patients between the ages of 18-65 classified as ASAI-II. The cases were randomized and divided into two groups. After giving fentanyl to patients in the first group and remifentanil infusion to patients in the second group, induction has administered by propofol and mivacurium was given as a muscle relaxant in both groups. After endotracheal intubation, systemic blood pressure, heart rate and peripheral oxygen saturation (SpO2) values were recorded every five minutes. When the surgery was completed, eye opening, following commands, saying her name, saying her birthday, sitting without help and getting the correct answer to the DSS test was recorded for both groups. Visual Pain Scale (VAS) and Modified Aldrete Score were evaluated and recorded at $0,15,30$, and 60 minutes. Patients were observed and recorded in terms of side effects such as increased secretion, bradycardia, nausea, vomiting, dizziness, headache, and tremors in both groups.

Results: In terms of demographic features there was no statistically significant difference between the two groups. Generally, systemic blood pressures were significantly higher in the fentanyl group. Heart rate was significantly higher in fentanyl group during intubation and intraoperative periods. There was no statistically significant difference between groups in terms of $\mathrm{Sp} 02$. Time until spontaneous breathing, extubating, eye opening, following commands, saying the name, DSST and unassisted sitting were significantly longer in the fentanyl group. The mean values of VAS scores at the 15th and 30th minutes were significantly higher in the remifentanil group. Similarly, the mean Aldrete recovery scale scores at 15 th and 30th minutes were significantly higher in the remifentanil group. When postoperative pathological findings were evaluated, the frequency of bradycardia was significantly higher in the remifentanil group, there was no difference in terms of other side effects.

Conclusion According to the our study results; we concluded that it is a better alternative to use remifentanil together with desflurane which is preferred short-acting inhalation agent in ambulatory anesthesia; in terms of hemodynamic stability during the intubation, peroperative and extubation periods and rapid postoperative recovery.
\end{abstract}

Key words: Remifentanil, Fentanyl, Day Case Surgery, Recovery, VAS, Aldrete

Suggested Citation: Dogan M, Gungordu E. Comparıson of The Effects of Remifentanil And Fentanyl Combıned with Desflurane on Intraoperatıve Hemodynamic Parameters and Postoperatıve Recovery Perıd in Anesthesia for Day Case Surgery. Middle Black Sea Journal of Health Science, 2020; 6(1):115-122 


\section{Address for correspondence/reprints:}

Murat Doğan

Telephone number: +90 (532) 5566645

ORCID-ID 0000-0003-2712-1497

E-mail: karderemd@hotmail.com

DOI: $10.19127 / \mathrm{mbsjohs.686947}$

\section{Introduction}

Ambulatory anesthesia includes admission of the patient to the hospital, surgery, recovery period and delivery to the home. The frequency of ambulatory anesthesia has increased from $10 \%$ to $55 \%$ since the 1980 s, and at least $17 \%$ has been applied under polyclinic conditions (American Hospital Association,2014). Day case surgery procedures are increasingly preferred in eligible patients due to lower costs, reducing length of hospital stay and shortening of waiting patient lists (Lapetina EM and Armstrong, 2002, Vila H et all. 2003, Coldiron B et all. 2004, Clayman MA et all. 2006). In addition to that, the increase of the role of anesthesiologists during the perioperative process, beginning to use of many short-acting anesthetic drugs, and increased use of minimal invasive surgical techniques are the other reasons. The presence of fast and short-acting anesthetic, analgesic and muscle relaxant agents allows many surgical interventions to be performed daily, thanks to this recovery will be easier and faster (Lapetina EM and Armstrong, 2002; Coldiron B et all. 2004; Shapiro et al,2014; Hüppe et al,2018; Barbier et al, 2019;). Propofol, which is one of the most preferred intravenous agents in ambulatory anesthesia induction, is one of the most suitable choices since it provides very fast recovery due to its short elimination half-life and early redistribution (Doze et al,1998). Since it isn't preferred to antagonize muscle relaxants, today the most popular agent in this respect is mivacurium, whose half-life is quite short, like 10-20 minutes (Cook et al,1989; Viby-Mogensen et all, 1995). Desflurane, one of the inhalation agents that frequently used in maintenance; by reason of its rapid induction and recovery and ensuring cardiovascular stability, it has become more often and widely used than other agents (White et al,2009). Remifentanyl and fentanyl which have rapid onset of action are widespread used as a narcotic agent, titratable, metabolised by non- specific esterases. Like other opioids, they can cause dose-dependent analgesia, respiratory depression, and muscle stiffness (Glass,1995; Mulas et al,1998). Recent years, many researches have been conducted to find the most appropriate combination among agents that have rapid onset of action, short recovery time and few side effects, provides amnesia and analgesia (Doris and Frances, 1999; Peacock,1999; Mulas et al,1998; Joo, 2000; Gelb AW et all, 2018). In our study, we used propofol as a hypnotic agent, mivacurium as a muscle relaxant, and desflurane in maintenance for ambulatory anesthesia of patients who have arthroscopic knee surgery. By comparing the effects of two different opioids, fentanyl and remifentanil with short-acting inhalation agent, desflurane on intraoperative hemodynamics and recovery quality in the postoperative period, we aimed to reveal whether they have superiority to each other.

\section{Methods}

A prospective randomized study planned as a thesis was carried out at Istanbul Education and Research Hospital with the approval of the local ethics committee between 2001-2002. 100 patients between the ages of 18-65, classified as American Society of Anesthesiologists Classification (ASA)III, who has arthroscopic knee surgery were included in the study. The patients were informed about the procedures to be performed before the operation; their approvals were obtained. Vascular access was obtained from the forearm veins with 22 Gauge $(G)$ intravenous (iv) cannula. Crystalloid infusion with the dose of $2 \mathrm{ml} / \mathrm{kg} /$ hour was started. Before induction, for the digit symbol substitution (DSS) test, we were informed that we would give a verbal warning such as a sentence or word, and that we would want it to repeat after the operation. No medication was used for premedication. Then DSS test was conducted to all patients. The cases were randomized and divided into two groups. After giving 1 microgram / kilogram ( $\mu \mathrm{g} / \mathrm{kg}$ ) fentanyl to patients in the first group, we preoxygenated patients with a mask for 3 minutes. In the second group of patients, subsequent to remifentanil $1 \mu \mathrm{g} / \mathrm{kg}$ bolus, $0.25 \mu \mathrm{g} / \mathrm{kg} / \mathrm{min}$ infusion was started. Induction has administered by 2 milligrams / kilogram $(\mathrm{mg} / \mathrm{kg})$ propofol in both groups. As a muscle relaxant, mivacurium was given in two steps, as priming dose before propofol, $0.15 \mathrm{mg} / \mathrm{kg}$ and then $0.10 \mathrm{mg} / \mathrm{kg}$. After ventilating with a mask for 2.5 minutes, endotracheal intubation was performed. After endotracheal intubation, maintenance was supplied with $50 \%$ Nitroprotoxide $(\mathrm{N} 2 \mathrm{O})+50 \%$ oxygen and 
4\% desflurane and mechanical ventilation was initiated. Systemic blood pressure (systolic, diastolic, mean), heart rate and peripheral oxygen saturation $(\mathrm{SpO} 2)$ values were recorded every five minutes. An additional dose of $0.5 \mu \mathrm{g} / \mathrm{kg}$ fentanyl was administered to the patients in group 1 , whose operation lasted more than 30 minutes. Remifentanil infusion rate was reduced to $0.05 \mu \mathrm{g} / \mathrm{kg} / \mathrm{min}$ after the 30th minute in patients in group 2 . When the surgery was completed, remifentanil infusion was terminated and desflurane was reduced to $2 \%$. Desflurane inhalation was stopped after skin suturization. Then N20 was ceased and switched to $100 \%$ oxygen. Duration of anesthesia was defined as the time from the moment of induction until the desflurane was ceased; the duration of the surgery was defined as from the moment of skin incision to removal of the trocars. The time from cessation of desflurane to extubation, eye opening, following commands, saying her name, saying her birthday, sitting without help and getting the correct answer to the DSS test were recorded for both groups. Visual Pain Scale (VAS) and Modified Aldrete Score were evaluated and recorded at $0,15,30$, and 60 minutes (Aldrete,1995; Katz and Melzack,1999). Patients were observed and recorded in terms of side effects such as increased secretion, bradycardia, nausea, vomiting, dizziness, headache, and tremors in both groups.

\section{Statistical Analyses}

SPSS 10.0 software (IBM, SPSS 10.0; Chicago, Illinois, USA) was used in the analysis. The mean, standard deviation, median minimum, median maximum, frequency and ratio values were used as descriptive statistics of the data. The distribution of variables was checked with the KolmogorovSmirnov test. The t-test and the Mann-Whitney Utest were used in the analysis of quantitative data for independent samples. The demographic data and intraoperative variables such as duration of surgery, between the two groups were analyzed using the Student's t -test for continuous variables. Chisquared test was used for categorical variables and the analysis of qualitative data. Hemodynamic parameters and scores at a particular point of time between two groups were compared, using unpaired $\mathrm{t}$-test. $\mathrm{p}$ - value $<0.05$ was regarded as statistically significant.

\section{Results}

Our study was planned as a randomized controlled study. In all, 100 patients between the ages of 18-65, classified as ASA I-II, had arthroscopic knee surgery in Istanbul Education Hospital between 2001-2002, were included in the study with the approval of the ethics committee. The mean age of the patients was 41.11. In terms of demographic features like age, average height and weight, gender, duration of anesthesia and surgery; there was no statistically significant difference between the two groups. ( $p>0.05)$ (Table 1).

Tablo 1. Comparison of demographic characteristics of the study groups.

\begin{tabular}{|c|c|c|c|c|c|}
\hline & \multicolumn{2}{|c|}{ REMIFENTANYL } & \multicolumn{2}{|c|}{ FENTANYL } & \multirow[t]{2}{*}{ p value } \\
\hline & Mean & SD & Mean & SD & \\
\hline Age $^{a}$ & 41.72 & 11.86 & 40.50 & 12.99 & .625 \\
\hline Weight ${ }^{\mathrm{a}}$ & 75.98 & 11.71 & 74.68 & 10.84 & .566 \\
\hline Length $^{\mathrm{a}}$ & 170.30 & 7.98 & 167.40 & 8.31 & .078 \\
\hline $\begin{array}{l}\text { Duration of anesthesia } \\
(\mathrm{min})^{\mathrm{a}}\end{array}$ & 34.18 & 6.10 & 35.24 & 7.90 & .428 \\
\hline \multirow[t]{2}{*}{$\begin{array}{l}\text { Duration of surgery } \\
(\min )^{\mathrm{a}}\end{array}$} & 24.18 & 4.94 & 25.28 & 7.38 & .347 \\
\hline & $\bar{n}$ & $\%$ & $\mathbf{n}$ & $\%$ & \\
\hline Gender $^{b}$ & & & & & .147 \\
\hline Women & 15 & 30 & 28 & 56 & \\
\hline Men & 35 & 70 & 22 & 44 & \\
\hline
\end{tabular}

\footnotetext{
${ }^{\mathrm{a}}$ Student t-test and ${ }^{\mathrm{b}}$ Chi-square, $*$ statiscally significant $\mathrm{p}<0.05$
} 
Tablo 2: Hemodynamic parameters during outpatient anesthesia

\begin{tabular}{|c|c|c|c|c|c|}
\hline & \multicolumn{2}{|c|}{ REMIFENTANYL } & \multicolumn{2}{|c|}{ FENTANYL } & \multirow[t]{2}{*}{ p value } \\
\hline & Mean & SD & Mean & SD & \\
\hline \multicolumn{6}{|l|}{ SBP(mmHg) } \\
\hline Preoperative & 143.26 & 15.83 & 148.12 & 18.14 & .157 \\
\hline Induction & 116.26 & 14.45 & 119.08 & 15.09 & .342 \\
\hline Intubation & 136.24 & 17.96 & 145.42 & 22.04 & $.025 *$ \\
\hline Intraoperative & 111.62 & 11.15 & 124.41 & 13.29 & $.000 *$ \\
\hline Pre-extubation & 129.74 & 13.79 & 139.84 & 17.42 & $.002 *$ \\
\hline Post-extubation & 143.70 & 13.61 & 151.42 & 18.60 & $.020 *$ \\
\hline Postoperative 15 minute & 139.82 & 13.03 & 143.06 & 15.49 & .260 \\
\hline Postoperative 30 minute & 138.20 & 11.62 & 137.70 & 16.08 & .859 \\
\hline Postoperative 60 minute & 137.06 & 12.04 & 138.78 & 16.26 & .549 \\
\hline \multicolumn{6}{|l|}{ DBP (mmHg) } \\
\hline Preoperative & 82.28 & 10.97 & 86.00 & 13.40 & .132 \\
\hline Induction & 65.70 & 10.50 & 69.58 & 12.62 & .098 \\
\hline Intubation & 78.90 & 12.71 & 85.66 & 15.80 & $.020 *$ \\
\hline Intraoperative & 63.30 & 9.00 & 71.77 & 11.95 & $.000 *$ \\
\hline Pre-extubation & 73.42 & 11.19 & 79.44 & 15.61 & $.029 *$ \\
\hline Post-extubation & 83.04 & 11.51 & 87.40 & 14.05 & .093 \\
\hline Postoperative 15 minute & 79.60 & 9.76 & 81.28 & 12.36 & .453 \\
\hline Postoperative 30 minute & 76.22 & 9.92 & 80.48 & 11.35 & $.048 *$ \\
\hline Postoperative 60 minute & 75.64 & 10.62 & 80.46 & 12.09 & $.037 *$ \\
\hline \multicolumn{6}{|l|}{ MBP (mmHg) } \\
\hline Preoperative & 105.37 & 14.95 & 108.78 & 15.54 & .268 \\
\hline Induction & 86.16 & 12.33 & 87.68 & 12.54 & .543 \\
\hline Intubation & 99.58 & 14.23 & 108.90 & 18.91 & $.006 *$ \\
\hline Intraoperative & 82.46 & 12.02 & 93.50 & 14.29 & $.000 *$ \\
\hline Pre-extubation & 95.54 & 14.96 & 101.92 & 18.84 & .065 \\
\hline Post-extubation & 104.98 & 12.89 & 113.30 & 17.48 & $.008 *$ \\
\hline Postoperative 15 minute & 99.72 & 9.44 & 102.38 & 12.80 & .240 \\
\hline Postoperative 30 minute & 96.42 & 9.35 & 99.64 & 12.19 & .142 \\
\hline Postoperative 60 minute & 95.06 & 10.25 & 99.58 & 12.29 & $.049 *$ \\
\hline \multicolumn{6}{|l|}{ HR/min } \\
\hline Preoperative & 84.62 & 12.34 & 89.20 & 12.11 & .064 \\
\hline Induction & 76.78 & 10.69 & 79.34 & 11.74 & .257 \\
\hline Intubation & 85.26 & 11.73 & 90.84 & 11.88 & $.020 *$ \\
\hline Intraoperative & 68.69 & 7.57 & 73.29 & 7.81 & $.004 *$ \\
\hline Pre-extubation & 79.80 & 9.82 & 82.40 & 9.46 & .181 \\
\hline Post-extubation & 92.08 & 10.03 & 93.00 & 10.76 & .659 \\
\hline Postoperative 15 minute & 85.06 & 7.05 & 86.78 & 10.69 & .345 \\
\hline Postoperative 30 minute & 82.54 & 6.14 & 84.54 & 8.79 & .190 \\
\hline $\begin{array}{l}\text { Postoperative } 60 \text { minute } \\
\end{array}$ & 80.94 & 5.99 & 82.90 & 9.98 & .237 \\
\hline \multicolumn{6}{|l|}{ SP02 (\%) } \\
\hline Preoperative & 97.40 & 1.17 & 96.14 & 4.20 & .370 \\
\hline Induction & 98.50 & 1.08 & 98.43 & 1.16 & .880 \\
\hline Intubation & 99.20 & 1.03 & 99.29 & 1.07 & .846 \\
\hline Intraoperative & 99.46 & .74 & 99.42 & .86 & .913 \\
\hline Pre-extubation & 99.50 & .71 & 99.46 & .88 & .911 \\
\hline Post-extubation & 98.00 & .82 & 98.54 & 1.27 & .256 \\
\hline Postoperative 15 minute & 97.90 & .57 & 97.92 & 1.26 & .958 \\
\hline Postoperative 30 minute & 97.89 & .60 & 97.77 & 1.30 & .800 \\
\hline Postoperative 60 minute & 97.78 & .67 & 97.92 & 1.19 & .744 \\
\hline
\end{tabular}

Student t-test, *statistically significant $\mathrm{p}<0.05$, SBP: systolic blood pressure, DBP:diastolic blood pressure, MAP: mean arterial pressure, HR: heart rate per minute, $\mathrm{SpO} 2$ : peripheral oxygen saturation 
Systolic blood pressure (SBP), diastolic blood pressure (DBP), mean arterial pressure (MAP), Heart rate (HR), oxygen saturation (SPO2) values were recorded preoperatively, in the course of induction and intubation, every five minutes during the intraoperative period, before and after extubation, and also at the 15th, 30th and 60th minutes in the postoperative period. As presented in Table 2; during intubation, in the perioperative period, before and after extubation, mean SBP were significantly higher in the fentanyl group ( $\mathrm{p}<0.05, \mathrm{p}<0.001, \mathrm{p}<0.01$ ). There was no significant difference between the two groups at 15, 30 and 60 minutes postoperatively ( $p>$ 0.05). Mean DBP were significantly higher in the fentanyl group in the course of intubation, during intraoperative period, before extubation, at $30 \mathrm{~min}$ and 60 min postoperatively $(\mathrm{p}<0.05, \mathrm{p}<0.001$, $\mathrm{p}$ $<0.01)$. There was no statistically significant difference between the two groups at preoperatively, at time of induction, post-extubation and postoperative 15th minutes ( $p>0.05$ ). Mean MAP was significantly higher in the fentanyl group during intubation, intraoperatively, post-extubation and postoperative 60th minutes. ( $p<0.05, p<0.001$ and $p$ $<0.01)$. There was no statistically significant difference preoperatively, at time of induction, preextubation, 15th and 30th minutes postoperatively ( $p>0.05)$. When the two groups were compared in terms of mean heart rate, there was no statistically significant difference preoperatively, at induction, before and after extubation, postoperative 15, 30 and 60 minutes ( $p>0.05$ ). However, heart rate was significantly higher in fentanyl group during intubation and intraoperative periods ( $\mathrm{p}<0.05$, p $<0.001$, p <0.01). There was no statistically significant difference between groups in terms of Sp02 (p>0.05) (Table 2).

Tablo 3: Findings of postoperative recovery period

\begin{tabular}{lccccc}
\hline & \multicolumn{2}{c}{ REMIFENTANYL } & \multicolumn{2}{c}{ pENTANYL } & \multicolumn{2}{c}{ palue } \\
\cline { 2 - 6 } & Mean & SD & Mean & SD & $.000^{*}$ \\
Spontaneous breathing & 3.57 & .67 & 5.73 & .77 & $.000^{*}$ \\
Extubation & 4.26 & .59 & 7.29 & 1.03 & $.001^{*}$ \\
Eye opening & 4.37 & .81 & 9.07 & 10.12 & $.000^{*}$ \\
Complying with command & 7.27 & 1.07 & 15.53 & 3.44 & $.000^{*}$ \\
Answering questions & 5.68 & .95 & 10.74 & 2.45 & $.000^{*}$ \\
DSST & 6.17 & .92 & 12.17 & 2.48 & $.000^{*}$ \\
Unaiding sitting & 12.25 & 1.47 & 24.12 & 5.44 & \\
\hline
\end{tabular}

Student t-test, *statistically significant $\mathrm{p}<0.05$, DSST: digit symbol substitution test

Tablo 4: VAS score averages

\begin{tabular}{lccccc}
\hline & \multicolumn{2}{c}{ REMIFENTANYL } & \multicolumn{2}{c}{ FENTANYL } & p value \\
\cline { 2 - 6 } & Mean & SD & Mean & SD & \\
\hline 0. minute & 4.10 & 2.31 & 3.68 & 2.07 & .341 \\
15. minute & $\mathbf{6 . 2 8}$ & $\mathbf{1 . 9 8}$ & 5.08 & 1.98 & $.003^{*}$ \\
30. minute & $\mathbf{7 . 1 4}$ & $\mathbf{1 . 4 8}$ & 6.08 & 1.85 & $.002^{*}$ \\
60. minute & 6.28 & 1.51 & 6.48 & 1.79 & .547 \\
\hline
\end{tabular}

Student t-test, *statistically significant $\mathrm{p}<0.05$, VAS: Visual analog scale

On the other hand, there was no statistically significant difference between the two groups in terms of mean values of systolic, diastolic, mean arterial pressure, and heart rate at time of induction, intubation, before and after extubation ( $p>0.05$ ). However, when both groups are analyzed separately; compared with values at induction, systolic, diastolic, mean arterial pressures and heart rate values were significantly increased during intubation and before extubation, except Sp02 ( $<<0.001, \mathrm{p}<0.05$ ). Sp02 values were significantly low $(\mathrm{p}<0.001, \mathrm{p}<0.05)$. As presented in Table 3, time until spontaneous breathing, extubation, eye opening, following commands, saying the name, DSST and unassisted sitting were significantly longer in the fentanyl group $(p<0.001)$. The mean values of VAS scores at the 15 th and 30th minutes were significantly higher in the remifentanil group $(\mathrm{p}<0.01)$ (Table 4). Similarly, the mean Aldreate recovery scale scores at 15 th and 30th minutes were significantly higher in the remifentanil group ( $\mathrm{p}<0.01$ ) (Table 5). When postoperative pathological findings were evaluated, the frequency of bradycardia was significantly higher in the remifentanil group, there was no statistically significant difference between the two groups in terms of other side effects $(\mathrm{p}<0.01, \mathrm{p}>0.05)$ (Table 6) 
Tablo 5: ALDRETE recovery scale score averages

\begin{tabular}{lccccc}
\hline \multicolumn{2}{c}{ REMIFENTANYL } & \multicolumn{2}{c}{ FENTANYL } & P value \\
\hline & Mean & SD & Mean & SD & \\
\hline 0. minute & 8.36 & .78 & 8.16 & .65 & .166 \\
15. minute & $\mathbf{9 . 6 8}$ & $\mathbf{. 5 1}$ & 8.88 & .82 & $.000^{*}$ \\
30. minute & $\mathbf{9 . 8 8}$ & $\mathbf{. 3 3}$ & 9.54 & .73 & $.004^{*}$ \\
60. minute & 9.96 & .20 & 9.86 & .35 & .082 \\
\hline
\end{tabular}

Student t-test, *statistically significant $\mathrm{p}<0.05$

Tablo 6: Pathological findings of postoperative recovery period

\begin{tabular}{lccccc}
\hline & \multicolumn{2}{c}{ REMIFENTANYL } & \multicolumn{2}{c}{ FENTANYL } & p value \\
\hline Increased secretion & $\mathbf{n}$ & $\mathbf{\%}$ & $\mathbf{n}$ & $\mathbf{\%}$ & \\
Laryngospasm & 4 & 8.0 & 3 & 6.0 & - \\
Nausea & 3 & 6.0 & 4 & 8.0 & - \\
Vomiting & 1 & 2.0 & 7 & 14.0 & 0.059 \\
Headache & 0 & - & 0 & & - \\
Dizziness & 3 & 6.0 & 6 & 12.0 & 0.487 \\
Shake & & & 3 & 6.0 & 0.242 \\
Bradycardia & 1 & $\mathbf{2 . 0}$ & 1 & $\mathbf{2 . 0}$ & - \\
\hline \multicolumn{1}{l}{ Student } & 17 & 34.0 & 5 & 10.0 & $0.007 *$ \\
\hline
\end{tabular}

Student t-testi, *statistically significant $\mathrm{p}<0.05$,

\section{Discussion}

Nowadays, the common features of the agents used in modern anesthesia practice are that their duration of action is short and therefore the anesthetic depth can be easily controlled, and they ensure the shorter and safer postoperative recovery period. With the widespread use of these agents, outpatient surgery has preferred and performed more frequently as a popular technique. We compared the effects of remifentanil and fentanyl in outpatient anesthesia. We didn't find any difference in Sp02 values between these opioids at any stage of anesthesia. However, in the fentanyl group, values of systolic, diastolic and mean blood pressures were detected higher, especially during intubation, intraoperative period, pre- and post-extubation periods, compared to remifentanil. In support of our data, some authors found SBP, DBP and MAP higher values in fentanyl group during intubation, intraoperative and extubation periods (Albertin et al,2001; Twersky et al, 2001; Lang et al, 2019). In contrast, some other authors reported that they could not find any significant difference between SBP, DBP and MAP in preoperative, peroperative and postoperative periods between administration of remifentanil 0.5 $\mathrm{mcg} / \mathrm{kg}$ bolus, $0.2 \mathrm{mcg} / \mathrm{kg} / \mathrm{min}$ infusion and fentanyl $1 \mathrm{mcg} / \mathrm{kg}$ bolus and $2 \mathrm{mcg} / \mathrm{kg} /$ hour infusion (Doyle et al,2001; Choi et al, 2016 ).It was thought that these results may be due to using different dosage and way of remifentanil and fentanyl.

When HR was evaluated in our study, it was found increased in the fentanyl group compared to the remifentanil group in the intubation and intraoperative period. Many authors were also found to similar results. In the remifentanil group, bradycardia was detected more frequently during intubation, preoperative and extubation period. When values were found below the 50 beat $/ \mathrm{min}$, intervened with atropine and these data were consistent with the literature (Cafiero et al,2000; Doyle et al,2001; Twersky et al, 2001; Choi et al, 2016).

When the findings of the postoperative recovery period are evaluated; in the fentanyl group, onset time of spontaneous breathing, extubation, eye opening, following commands, saying the name, DSST, and unaided sitting were found to be significantly longer. These values were found to be compatible with other remifentanil-fentanyl comparative studies (Mulas et al,1998; Doyle et al,2001, Dy et al, 2001; Grundmnann et al, 2001). Similarly, some authors compared combination desflurane-remifentanil to desflurane-fentanyl; in remifentanil group, they found that onset time of spontaneous breathing, extubation, eye opening, saying the name, and following the commands are significantly shorter. They also reported that they found DSST duration significantly shorter in the remifentanil group (Wilhelm et al,2001). But the others were found no difference between them (Choi et al, 2016). While the VAS scores that we used to evaluate postoperative pain were statistically significantly higher in the remifentanil group at 15 th and 30th minutes, we didn't find any significant difference at the 60th minute. In their study with 16 patients from the remifentanil and fentanyl groups, some authors reported that 7 patients in the remifentanil group and 
4 patients in the fentanyl group had analgesic requirements in the early post-operative period (Doyle et al,2001). But the others found no difference VAS scores between fentanyl and remifentanil group in their studies (Haytural, 2015). On the other hand; some other authors found higher VAS scores in the fentanyl group (Monsef et al, 2019).We didn't administer additional analgesics in our study, but when the VAS scores were evaluated, it was concluded that pain control was better achieved in patients treated with fentanyl in the early period.

The average of Aldrete score used for assessment of the cooperation of the patients in remifentanil group at the 15th and 30th minutes during the recovery period were found significantly higher. At 0 and 60 minutes, the score results were similar. When the pathological findings were evaluated, 4 patients in the remifentanil group had increased secretion, 3 patients had laryngospasm, 1 patient had nausea and 3 patients had headache. Increased secretion in 3 patients, laryngospasm in 4 patients, nausea in 7 patients, and headache in 6 patients were detected in the fentanyl group. However, there was no significant difference between the two groups in terms of these parameters. These findings were consistent with the literature. Similar findings are declared between the two groups in the many studies (Mulas et al,1998; Doyle et al,2001; Haytural, 2015, Monsef et al, 2019).

\section{Conclusion}

According to the results we obtained from our study; we concluded that it is a better alternative to use remifentanil together with desflurane which is preferred short-acting inhalation agent in ambulatory anesthesia; in terms of hemodynamic stability during the intubation, peroperative and extubation periods and rapid postoperative recovery.
Ethics Committee Approval: Ethics committee approval was received for this study from Clinical Research Ethics Committee of Istanbul Teaching and Research Hospital.

Peer-review: Externally peer-reviewed.

Author Contributions: Concept - M.D Design M.D; Supervision M.D; Materials - M.D; Data Collection and/or Processing - M.D; Analysis and/or Interpretation - M.D; Literature Review - M.D,E.G; Writing - M.D,E.G; Critical Review -M.D

Acknowledgements: There are no acknowledgements or fundings to declare.

Conflict of Interest: No conflict of interest was declared by the authors.

Financial Disclosure: The authors declared that this study hasn't received no financial support.

\section{References}

Albertin A, Casati A, Deni F, Danelli G, Comotti R, Grifoni F, Fanelli G: Clinical comparison of either small doses of fentanyl or remifentanyl for bulunting cardiovascular changes induced by tracheal intubation. MinervaAnestesiologica, 66(10): 691-696, 2001.

American Hospital Association; The Migration of Care to Non-hospital Settings: Have Regulatory Structures Kept Pace with Changes in Care Delivery?; July 2006. (Accessed on June 08, 2014).

Barbier D, N'Dele D, Bennis M, Thevenin-Lemoine C. Et al, Day surgery for anterior cruciate ligament reconstruction in children: a prospective study on feasibility and satisfaction. J Child Orthop. 2019 Feb 1;13(1):100-106.

Cafiero T, Mastronardi P, Burrelli R, Santoro R: The effects of remifentanil on hemodinamic response to intubation. A comparative study with fentanil. MinervaAnestesiol 2000 Nov; 66(11): 793-7.

Choi JW, Joo JD, Kim DW, et al; Comparison of an Intraoperative Infusion of Dexmedetomidine, Fentanyl, and Remifentanil on Perioperative Hemodynamics, Sedation Quality, and Postoperative Pain Control. J Korean Med Sci. 2016 Sep;31(9):1485-90.

Clayman MA, Seagle BM. Office surgery safety: the myths and truths behind the Florida moratoria--six years of Florida data. Plast Reconstr Surg 2006; 118:777.

Coldiron B, Shreve E, Balkrishnan R. Patient injuries from surgical procedures performed in medical offices: three years of Florida data. Dermatol Surg 2004; 30:1435. 
Cook DR Stiller R1. İn vitro metabolism of mivacurium chioride, Anaesth. Analg. $1989 ; 68$ $: 452-456$

Dershwitz M, RandelGl, Rosovv CE, Fragen RJ, et al: Initial clinical experience with remifentanyl, a new opioid metabolized by esterases. Anesth. Analg. 81:619, 1995

Doris T, Frances C. Postoperative pain control in ambulatory surgery. Surg Clinics of North America. 1999 April; 79(2): 401

Doyle PW, Coles JP, Leary TM, Brazier P, Gupta $\mathrm{AK}$ : A comparison of remifentanil and fentanil in patients undergoing carotid endarterectomy. Eur J Anaesthesiol 2001 Jan; 18(1): 13-9

Doze V.A., Shafer A., White P.F: Propofol-nitrous oxide versus thiopental-isoflurane-nitrous oxide for general anesthesia. Anesthesiology 69; 63-71, 1998

Dy EA, Lovely LK, Graziano GP, Samra SK, Welch KB: Remifentanil and fentanil based anesthesia of somatosensory evoked potentiais. Anesthesia and Analgesia, 92(6): 1510-5, 2001

Gelb AW, Morriss WW, Johnson W, et al. World Health Organization-World Federation of Societies of Anaesthesiologists (WHO-WFSA) International Standards for a Safe Practice of Anesthesia. Anesth Analg 2018; 126:2047.

Glass PSA: Pharmacology of remifentanil. European Journal of Anaesthesiology $12: 73,1995$

Grundmann U, Siiomon M, Bach F, Becker S, Bauer M, Larsen B, Kleinschmidt S: Recovery profile and side effects of remifentanil-based anaesthesia with desfluran or propofol for laporoscopic cholesystectomy. Açta Anaesthesiol Scand 2001 Mar; 45(3): 320-6

Haytural C, Aydınlı B, Demir B, et al. Comparison of Propofol, Propofol-Remifentanil, and PropofolFentanyl Administrations with Each Other Used for the Sedation of Patients to UndergoERCP. Biomed Res Int. 2015;2015:465465.

Hüppe T, Kneller N, Raddatz A.Upper Age Limit in Outpatient Anesthesia: Opportunities and Risks. Anasthesiol Intensivmed Notfallmed Schmerzther. 2018 May;53(5):380-386.

Joo HS. Sevoflurane versus propofol for anesthetic induction:a meta- analysis. Anesth Analg-2000 Jul;91(1);213-9
Lang B, Zhang L, Li F, Lin Y, Zhang W, Yang C. Comparison of the efficacy and safety of remifentanil versus different pharmacological approaches on prevention of etomidate-induced myoclonus: a meta-analysis of randomized controlled trials. Drug Des Devel Ther. 2019 May 9;13:1593-1607.

Lapetina EM, Armstrong EM. Preventing errors in the outpatient setting: a tale of three states. Health Aff 2002; 21:26.

Measurement of pain.Katz J, Melzack R Surg Clin North Am. 1999 Apr; 79(2):231-52.

The post-anesthesia recovery score revisited. Aldrete JA J Clin Anesth. 1995 Feb; 7(1):89-91.

Monsef Kasmaee V, Zia Zibari SM), Aghajani Nargesi M. Remifentanil versus Propofol/Fentanyl Combination in Procedural Sedation for Dislocated Shoulder Reduction; a Clinical Trial. Arch Acad Emerg Med. 2019 Jan 25;7(1).

Mulas M, Sances D, Sabbia E, Pala G, Ruiu P: Remifentanil vs fentanyl in ultrashort gynaecological day surgery. Br. J. Anaesth 80: 12, 1998

Peacock JE: Ambulatory anesthesia experience with remifentanil. Anesth Analg-1999 Oct;89 . 22-7

Shapiro FE, Punwani N, Rosenberg NM, et al. Officebased anesthesia: safety and outcomes. Anesth Analg 2014; 119:276.

Twersky RS, Jamerson B, Wamer DS, Fieisher LA, Hogue S: Hemodynamics and emergenceptofile of remifentanil versus fentanil prospectively compared in a large population of surgical patients, J ClinAnesth 2001 Sep; 13(6): 407-16

Viby-Mogensen J. Jargensen B. Reversal of intense mivacurium block with human plasma cholinesterase in patients with atypical PCHE. Anaesth. $1995 ; 82$ : 1295-1298

Vila H Jr, Soto R, Cantor AB, Mackey D. Comparative outcomes analysis of procedures performed in physician offices and ambulatory surgery centers. Arch Surg 2003; 138:991.

White PF, Tang J, Wender RH, et al. Desflurane versus sevoflurane for maintenance of outpatient anesthesia: the effect on early versus late recovery and perioperative coughing. Anesth Analg 2009; 109:387.

Wilhelm W, Schlaich N, Harrer J, Kleinschmidt S, Müller M, Larsen R: Recovery and neurological examination after remifentanil-desfluran or fentanyl-desfluran anaesthesia for carotid artery surgery. Br. J. Anesthesia86 (1): 44-9, 2001 